\title{
Content Validity of e-Psychological Testing Version-I for Effective Flood Victims' Mental Health Digital Management
}

\section{A. Nazilah ${ }^{1 *}$, Nor Aizal Akmal Rohaizad", Raja Zirwatul Aida Raja Ibrahim", Mazidah Dagang ${ }^{1}$, Syaidatun Nazirah Abu Zahrin ${ }^{2}$}

\author{
${ }^{1}$ Psychology and Counseling Department, School of Social and Economic Development, \\ University Malaysia Terengganu, Malaysia \\ ${ }^{2}$ Pusat Citra Universiti, Universiti Kebangsaan Malaysia, Selangor Darul Ehsan, Malaysia \\ ${ }^{*}$ Corresponding author: nazilah@umt.edu.my
}

Keywords: e-Psychological testing; mental health digital management; flood victims; validity.

\begin{abstract}
Floods are classified among sudden onset phenomenon and the highest natural disasters happen in Malaysia. Floods have a negative impact on mental health. Mental distress intervention and treatment need to a valid and reliable test to measure its symptoms. In Malaysia, there is a lack of such test. The psychological testing which is meant for clinical setting uses also requires a more accurate test. Therefore, the objective of this study is to replicate the earlier studies of developing e-Psychological Instrument for Flood Victims Version I (e-PIFV-I). The e-PIFV-I is a self-report test which is administered digitally. It has four sub scales; stress, anxiety, depression and trauma. The test is formed for mobile platform purposes which supports android systems. Two replicated studies (study I and study II) have been done to validate the test by using expert judgment method. Results showed that content coefficient validity for each sub-scale of the test ranging from moderate to very strong validity. The coefficient value for the two subscales and the overall scale in study II were increased. This study has theoretical and practical implication in the field of e-testing, clinical psychology and flood digital management.
\end{abstract}

\section{Introduction}

Floods are worldwide natural disasters and have caused a high mortality rate in poor countries. Floods are classified among sudden onset phenomenon and the highest natural disasters happen in Malaysia. In 2014, floods hit several states on the east coast of Peninsular Malaysia. This phenomenon has caused a negative impact on victims' mental health and well-being. Therefore, the issue of floods in Malaysia needs to be managed effectively. In addition, mental distress in Malaysia has increased. Reports show that the environmental factor is one of the factors that may contribute to mental distress over the past 10 years [1]. Due to the current alarming mental distress in Malaysia, the minister suggests to find methods to identify early signs of mental distress. Therefore, a psychological testing to help people to identify the symptoms of mental distress individually and promptly is necessary.

Based on literatures, tests for measuring stress, anxiety, depression and trauma get attention in various sectors because of the importance of mental health issues. However, there are lacks of such tests that are designed to be used in developing countries such as Malaysia. Furthermore, test which is developed in other cultures has its limitations and needs to make a proper adaptation [2]. Yet, people and cultures have their own distinct characteristics and influence one and another [3]. 
Furthermore, adapted versions of mental distress tests for Malaysian use are very few [4]. Most of the tests also use paper and pencil form [5]-[12]. The major weakness of paper and pencil method is the test score cannot be obtained immediately. In addition, flood researchers have suggested to have an effective flood management system particularly in Malaysia [13].

\section{Methods}

This study was a replicated study of e-IPFV-I to confirm the past results. The e-PIFV-I is a test to measure stress, anxiety, depression and trauma among flood victims. The test is suitable for flood victims aged 12 years old and above. It is designed as a digital self-administered test for non-illiterate individuals. The e-IPFV-I is formed using the Ionic Framework for mobile platform purpose which supports android systems version 3.0 and above. Basically, the e-IPFV-I test user has 7 steps to follow. First, click the e-IPFV icon on your android device. Second, enter the user name. Third, enter the location. Fourth, choose "e-IPFV-I" or "e-IPFV-II" in configuration menu. Fifth, click the menu and select "Section A" to answer all questions about demographic information. You have to insert your identity number or any numbers (if you want to hide your identity) before you can start answer in this section. Sixth, click the menu and select "Section B" to answer all questions about mental distress. Seventh, click the menu and select "Results" to see your score. The e-PIFV-I takes 20 - 25 minutes to be completed.

Based on the past studies, several items in the e-PIFV-I were improved based on experts comments and suggestion on words and sentences used in particular. These two studies were conducted to review and revalidate the test through an expert assessment statistical method to get the content coefficient validity index [14].

\section{Results and Discussion}

In study I, the e-IPFV-I had a moderate to high content coefficient validity. In study II, the coefficient value for two subscales and overall scale were increased from moderate to a high content validity (Table I). It is a good effort to replicate content validity study in order to improve its content validity. It is not only required in scientific research but also is a need in psychological testing field especially for clinical setting purposes.

Table I: Content coefficient of e-IPFV-I

\begin{tabular}{lccccc}
\hline Study & Stress subscale & Anxiety subscale & Depression subscale & Trauma subscale & Overall scale \\
\hline Study I & 0.7 & 0.9 & 1 & 0.6 & 0.8 \\
Study II & 0.8 & 0.9 & 1 & 0.8 & 0.9 \\
\hline
\end{tabular}

The e-IPFV-I has 84 items with four subscales and each subscale has 21 items. The example of stress symptoms are "I feel depressed", "I get upset easily", "My mind is chaotic", "The muscles in my body feel tense" and "I am having difficulty to calm myself down". The example of anxiety symptoms are "I often panic", "I breathe rapidly", "I find it difficult to relax", "I often feel goose bumps" and "I feel uneasy in the stomach". The example of depression symptoms are 'I get tired easily", "I think slowly", "I feel hopeless", "My memory is deteriorating" and "My reaction is slow". 
The example of trauma symptoms are "I feel unstable", "I keep on seeing flood images", "I refuse to think about flood", "I am in panic state whenever it rains heavily" and "I feel helpless to deal with flood disaster".

\section{Conclusion}

The present study shows that the improvement of the content validity of e-IPFV-I. The coefficient values for all subscales of the test improve from moderate to the high level. The test supports the literatures of stress, depression, anxiety and trauma of the multiple types of reactions of the four constructs [15]-[21]. Hopefully, the e-PIFV-I will become an effective social innovation in terms of digital test to measure flood victims' mental distress particularly among Malaysians. It is an alternative to offer an effective solution to the Malaysian to cater mental health issues particularly for flood victims. This test also will help to overcome the limitation of time and experts to screen mental distress symptoms among the flood victims. This study has generalization weakness. Therefore, flood victims from diverse backgrounds and cultures should be included in future research. This study also has the limitation of construct validity. Therefore, the researchers suggest to do construct validation study in the future.

\section{Acknowledgment}

The study was supported by the Research Management and Innovation Centre, University Malaysia Terengganu [grant number 50001].

\section{References}

[1] Minister of Health Malaysia. Press Statement, Mental Health Problems in Malaysia. September 28, 2016.

[2] Goh, P.S.C., Wong, K.T. \& Mahizer, H. (2017) Re-structuring the revised two-factor study process questionnaire (R-SPQ-2F) in the context of pre-service teachers in Malaysia. Pertanika Journal of Social Sciences and Humanities, 25 (2), 805-821.

[3] Morris, C.G. \& Albert A. Maisto, A.A. (2016) Understanding Psychology (11ed). Upper Saddle River, N.J Prentice Hall.

[4] Musa, R., Fadzil M.A., Zain, Z. (2017) Translation, validation and psychometric properties of Bahasa Malaysia version of the Depression, Anxiety and Stress Scales (DASS). ASEAN Journal of Psychiatry, 8 (2):82-89.

[5] Othman, A. Z., Dahlan, A., Borhani, S. N., \& Rusdi, H. (2016) Posttraumatic stress disorder and quality of life among flood disaster victims. Procedia-Social and Behavioural Sciences, 234, 125-134.

[6] Abdullah, S., Sipon, S., Nazli, N. N. N. N., \& Puwasa, N. H. (2015). The relationship between stress and social support among flood victims. Procedia-Social and Behavioural Sciences, 192, 59-64. 
[7] Sipon, S., Sakdan, M. F. A., Mustaffa, C. S., Marzuki, N. A., Khalid, M. S., Ariffin, M. T. \& Abdullah, S. (2015) Spirituality among flood victims: A comparison between two states. Procedia-Social and Behavioral Sciences, 185, 357-360.

[8] Mustaffa, C. S., Marzuki, N. A., Ariffin, M. T., Salleh, N. A., \& Rahaman, N. H. (2014) Relationship between social support, impression management and well-being among flood victims in Malaysia. Procedia-Social and Behavioral Sciences, 155, 197-202.

[9] Sipon, S., Nasrah, S. K., Nazli, N. N. N. N., Abdullah, S., \& Othman, K. (2014) Stress and religious coping among flood victims. Procedia Social and Behavioral Sciences, 140, 605-608.

[10] Sauer, S., Ziegler, M., \& Schmitt, M. (2013) Rasch analysis of a simplified Beck Depression Inventory. Personality and Individual Differences, 54 (4), 530-535.

[11] Lee, E. H. (2012) Review of the psychometric evidence of the perceived stress scale. Asian Nursing Research, 6 (4), 121-127.

[12] Elklit, A., Karstoft, K. I., Lahav, Y., \& Andersen, T. E. (2016) Attachment and posttraumatic stress disorder in multiple trauma samples. Journal of Psychiatry, 19: 370. doi:10.4172/2378-5756.1000370.

[13] Hussain, T.P.R.S., Nor, A.R.M. \& Ismail, H. (2014) The level of satisfaction towards flood management system in Kelantan, Malaysia. Pertanika Journal of Social Science and Humanities, 22(1), pp. 257-269.

[14] Cohen, R. J., Swerdlik, M. \& Sturman, E.D. (2013) Psychological Testing and Assessment: An Introduction to Tests and Measurement ( $8^{\text {th }}$ ed.). New York: McGraw-Hill.

[15] Reyes, G., Elhai, J.D. \& J.D. (Eds) (2008) The Encyclopedia of Psychological Trauma. John Wiley \& Sons.

[16] Taylor, S.E. (2002) Health psychology (5th ed.). New York: McGraw-Hill.

[17] Ganzel, B.L., Morris, P.A., \& Wethington, E. (2010) Allostais and the human brain: Integrating models of stress from the social and life sciences. Psychological Review, 117, 134-174.

[18] Lazarus, R.S., \& Folkman, S. (1984) Stress, appraisal and coping. New York: Springer.

[19] Andrews, L. W. (Ed.) (2010) Encyclopedia of Depression (Vol 1-2). Santa Barbara, California: Greenwood.

[20] Encyclopedia of Britannica, (2018). Retrieved February 8, 2018 from https://www.britannica.com/topic/stress-psychology-and-biology.

[21] Kazdin, L.E. (2000) Encyclopedia of Psychology. American Psychological Association. 